Pakistan Journal of Humanities and Social Sciences

October - December 2019, Volume 7, No. 4, Pages 365 - 377

\title{
Nominative and Accusative Cases in English and Urdu: A Comparative Study
}

\author{
Faiza Zeb
}

${ }^{1} \mathrm{PhD}$ Scholar, National University of Modern Languages, Islamabad, Pakistan

Email: fzeb@numl.edu.pk

\begin{abstract}
Languages show variations in terms of their syntactic patterns. Their comparison reveals the effective strategies to explore and illustrate the difficulties that language learners may come across in the course of acquiring any new language. This study aims at the exploration of nominative and accusative properties in English and Urdu with the help of Chomsky's Case theory as first introduced within the boundaries of the Government and Binding theory in 1981. It effectively presents the properties of any nouns in order to be declared as either nominative or accusative cases in any languages. Along with the case theory, the researcher has used qualitative and further the descriptive and content analysis approach as applied to the few English sentences taken from the New Headway Workbook by Liz and John Soars, meant for language learners at Elementary level. The study presents the thorough analysis of few English sentences and their Urdu translations to highlight similarities and differences as present in English and Urdu nominatives and accusatives in relation to other parts of speech as these properties haven't been explored by the previous researches instead the focus has been on ergativity in Urdu.
\end{abstract}

Keywords: Nominative case, Accusative case, Chomsky's Case Theory, English, and Urdu

\section{Introduction}

The term "Case" has been defined as "a system of marking dependent nouns for the type of relationship they bear to their heads (Blake, Barry J. Case. Cambridge University Press: 2001)." The morphology that is considered to be associated with grammatical relations is called case (Carnie, Andrew. Blackwell Publishers Oxford: 2001). Here, the Cases should be distinguished from the thematic roles, as cases are morphological categories, whereas thematic roles are semantic in nature. 
Thematic roles represent meaning, whereas Cases represent how an NP functions grammatically in the sentence. Any NP, noun or pronoun that serves as subject of a sentence, and is not administered by any case marker, tends to bear a Nominative case. For instance, in the following examples" Khurram, he, they, we, and it, " serve as the subjects of the sentences and they do not bear any case marker, so declared as Nominative case.

- Khurram eats cakes.

- We play cricket.

- It rains (cf, Mirza, 2014).

Moreover, a noun or pronoun that serves as the object of a sentence, and is not governed with any case marker, assumes to take Accusative case. In the following examples: "her, Akhter, and the room" take the position of the object of a sentence so they possess an "Accusative case (cf, Mirza, 2014):

- Hina helped her.

- Shehzad hit Akhtar.

- They came into the room(cf.Mirza, 2014).

Case theory was first given within the premises of Government and Binding theory and supposed to possess a special property that all noun phrases should have and if they seem lacking this feature, the sentence which contains the noun phrase is taken to be ungrammatical. There are two Cases that are usually provided and accepted in English language: nominative Case and accusative Case, the later is also termed as the objective Case (DeArmond, 2002). Case Theory assumes that the cases which are found with subject of a sentence are Nominative whereas those found with objects of a sentence are Accusative (Chomsky, 1981).

Chomsky (1981, p. 48) suggests that nominative case is allocated to the subject of a tensed sentence only. In a tensed sentence, the subject always takes a nominative case, like it has taken in the example A (as given below), but it cannot take in a non-tensed sentence as shown in example B. In these examples, the only choice then is for the verb to assign an accusative case to the subject of the embedded verb, and thus creating accusative along with infinitive construction, as it is presented in example C (Chomsky, 1981).

- Cem believes they are a good rock band.

- *Cem believed they to be a good rock band.

- Cem believed them to be a good rock band. 
Languages show variations in terms of their arguments. Lexical and syntactic conditions do exist on specific cases. They are also different in the way the arguments of a verb are presented syntactically, as subject or objects or oblique arguments exist in any languages. In many of the languages, subject mark nominative case on the noun phrase and person or number agreement on the finite verb. Urdu language agrees to this system partly since Finite verb agreement is only found to be in nominative Determiner Phrases. This is not a strange limitation in languages where there is a single set of agreement patterns (number, gender or person), as mirrored on the verbal complex consisting of verb and tense and aspect inflection (Davison 2003).

Furthermore, Case is inbuilt in Verbs and Preposition but is by no means realized phonetically. The value of Case is always taken to be nominative in English verbs and prepositions. This work will draw the comparison between English and Urdu sentences by making in-depth and thorough analysis of different English and Urdu sentences. The Accusative and Nominative Cases, Verbs and prepositions, and, adjectives and nouns are analyzed by applying Chomsky Case theory.

Urdu is a South Asian language spoken in Pakistan as a national language and in India as one of the eighteen official languages. The grammatical pattern that Urdu possesses is that of (SOV), subject, and object agreement but if there is a non-nominative case then it includes an ergative. While dealing with Clause Structure of this language we find everything as head-final, with exception of few complementizers (cf. Bayer 1999). Unlike English there is No definite determiner and Specificity is marked by means of the accusative case clitic "ko",that is also found in Turkish (Enc, 1991). Moreover in some situations we also see Adjectives as making agreement in number and gender with the noun. In Urdu one can find Quantifiers too as pre-nominal, however they sometimes appear post nominally.

This research is going to explore the grammatical properties of Urdu language in comparison with English language but it aims at exploration of similarities and differences in terms of nominative and accusative properties of English and Urdu which haven't been explored earlier in terms of their relation with other grammatical categories or parts of speech such as verb, adjectives and prepositions and also haven't been explored in terms of purely being nominative and accusative.

Research Question is as follows;

How do English and Urdu languages differ from each other in terms of their Nominative and Accusative properties? 
The research has been delimited to:

- Chomsky's case theory since the purpose is only to bring into light the similarities and differences in nominative and accusative properties of English and Urdu to develop the better understanding of both among the language learners.

- Few specific examples from New Headway Workbook meant for Elementary Level of language learners due to time constraint.

The research aims at the following objectives:

- To find out the similarities and differences between English nominative and accusative properties.

- To investigate the differences and similarities of nominative and accusative properties in relation to other parts of speech such as Verbs, adjectives and prepositions.

- To develop the better understanding of the difficulties that English language learners face due to their ignorance of the variations in English and Urdu nominative and accusative cases.

This study aims at bringing into light the various aspects of English nominative and accusative properties which have not been purely analyzed in terms of purely their sole purpose of being nominative or accusative. Previous researches emphasized the various cases of Urdu and also their comparison with English cases but no research put the elements of purely nominative and accusative properties of English in terms of their comparison with Urdu language.

This research aims at exploration of similarities and differences between English and Urdu in terms of their nominative and accusative properties by making their relation to other parts of speech such as verb, adjective and preposition so that English language learners can better cope up with difficulties of English language by not bringing into account their native Urdu language at all times. They will have realization of the differences of both the languages in terms of their accusative and nominative properties.

This research will also be useful to understand how different language teaching methodologies can be adopted and adapted as per students' background of English language by observing the nominative and accusative properties as existing in their native language and a foreign or second language and this in turn will lead to the effective process of language learning which has always been taken as stressing and depressing for language learners due to lack of understanding of basic target language rules or grammar. 


\section{Literature Review}

Oxford English Dictionary defines Noun as "A word used as the name or designation of a person, place, or thing; the class or category of such words." Word Net describes noun in two categories: semantically and functionally. Semantically it can be "a content word which in turn could to refer to a person, place, thing, quality, or action", and functionally it refers to "the word class that can serve as the subject or object of a verb. (cf.Ali, Hussain, Malik \& Siddeeq).

Masica(1991) states that Nominative case is a fixed standard for subject status in English and a number of other languages. In finite clauses, it is the single case possibility yet in languages with other case possibilities for Subject; a nominative case does not exclusively mark grammatical subjects.

According to Masica(1991) and Mohanan(1994), Hindi and Urdu have got such subjects which cannot be taken as nominative(cf. Davison, 2001). According to them, Some specific verb phrases in Urdu and Hindi language require dative "-koo" or other postpositional subjects for instance the location expressions such as -par (on) -mee ('in) can be found with subject of finite verb and genitive -kaa also exists at times and there can be found the instrumental -see or sai. The agent phrase with the genitive -see as called "with: in English or also "by" has subject properties in some passive construction of sentences. Additionally, subjects of most transitive verbs often entail the ergative postposition -nee in finite clauses which have got the perfective aspect, and there doesn't exist any auxiliary verbs which can obstruct ergative cases. A few intransitive verbs permit ergative subjects under the similar circumstances as transitive verbs. Also some nonfinite clauses may have genitive subjects for instance: infinitives and participles; or dative subjects such as participial subjects in Exceptional Case Marking constructions (cf. Davison, 2001).

According to Davison (2001), Hindi and Urdu are such languages where nominative direct objects are frequent, in addition to nominals which are ingredient of Noun and verb complex predicates. In these languages, nominative case refers to the absence of a postposition, plus a direct morphological form. The 'oblique' morphological form is made necessary by the presence of postpositions (Davison, 2001).

According to Butt and King (2001), in Urdu language there can be found six cases. For instance: Nominative (it is the same case as we find in English language too), Accusative case has got the category of "ko", ergative case refers to the category of "ne" and instrumental case is "se" and locative is "me, tuk, per, etc (Butt \& King, 2001). 
Durrani assessed Urdu as a split-ergative language. His analysis was relied upon the standard check-list of three essential factors: case markers, verb agreement, and constituent order which were also used by Thomas E. Payne by building a 3 X 3 matrix. S, A and $\mathbf{O}$ function at $\mathbf{x}$-axis and the variables as mentioned above operate at $\mathbf{y}$-axis. Performance of $\mathbf{S}$, $\mathbf{A}$ and $\mathbf{O}$ is observed against each y-axis entry. He found out that a split pattern in Urdu is triggered by ergative case marking. The ergative case marker is requirement of perfective tense which does not allow nominative case marking to occur on subjects. But for other cases there are agents which definitely come into view as nominative case (Durrani).

Additionally, in Urdu language, a split takes place as flanked by an imperfect aspect and a perfect aspect. A verb that takes place in the perfect aspect establishes its arguments using an ergative system, whilst the imperfect aspect generates accusative marking. Urdu, too, has got an ergative case on agents when we find perfective aspect for transitive as well as ditransitive verbs. So the split-ergativity in Urdu is generated by the case-markers in particular by ergative which become visible on the subjects of transitive verbs in case of perfect morphology (cf. Durrani). Yet there is no work done on finding similarities and differences between English and Urdu languages that how they differ from each other in terms of their nominative and accusative properties particularly and how understanding of the differences can lead to better understanding of English grammatical structures for those people who learn English as second or a foreign language.

\section{Research Methodology}

\subsection{Research design}

This study takes qualitative descriptive approach and further the research method of content analysis to analyze the various examples of English sentences from New Headway Elementary level as designed for English Language learners. Qualitative Research is first and foremost an exploratory type of research. It is employed to get an understanding of essential reasons and opinions. It provides insights into the problem and is also used to reveal developments in idea and beliefs, along with diving deeper into the predicament. Qualitative data collection methods differ by means of unstructured or semi-structured techniques. A number of familiar methods contain group discussions, individual interviews, and observations. The size of the sample is in general small, and respondents are chosen to accomplish an agreed part (Wyse, 2011).

Qualitative content analysis is one of frequent research methods which are used to analyze text data. Further some methods may include: ethnography, grounded theory, 
phenomenology, and historical research etc. Research conducted via qualitative content analysis pays attention on the distinctiveness of language as communication so that to uncover the content or contextual meaning of the text under consideration (cf. Hsieh \& Shannon, 2005).

Text data can be in various forms such as in verbal, print, or electronic form etc. and may have been attained from narrative responses, open-ended survey questions, interviews, focus groups, observations, or print media such as articles, books, or manuals (Kondracki \& Wellman, 2002). Qualitative content analysis is not just from counting words to investigating language deeply with the aim to classify large amounts of text into a well-organized number of categories which are able to correspond to related meanings (Weber, 1990). The objective of content analysis is "to provide knowledge and understanding of the phenomenon under study" (Downe-Wamboldt, 1992, p. 314).

Moreover, the descriptive research has got three main principles of research: to describe, explain, and then authenticate the findings. Description materializes following ingenious exploration, and then aims at organizing the findings in order to make them appropriate with explanations (Krathwohl, 1993). In this article, qualitative content analysis and further descriptive approach is employed so as to do the subjective interpretation of the content of the data of the text as taken from New Headway (meant for Elementary level for English language learners) in the course of the systematic classification process.

\subsection{Research Sample}

The researcher has chosen the workbook of New Headway for Elementary level by Liz and John Soars (2003) as used by English Language learners who are considered to be beginners in the language learning process. Only few exercises and examples have been chosen to describe and illustrate nominative and accusative cases in English language. Further the translation of these sentences has been used to make comparison of the English sentences with sentences of Urdu language.

\subsection{Rationale for the Selection of the Research Sample}

Headway series are taken to be very famous series by language teachers and academicians for language learners and its different editions are used at different levels of English language learning process at different academic institutions. Only few examples have been taken from English language learning book "New Headway for Elementary level" by Liz and John Soars due to time constraint. In case of more time available to the researchers, 
they can focus on all the different editions of the Headway Series by Liz and John Soars(2003).

\section{Theoretical Framework}

According to Chomsky (1981, p. 48), case is assigned under the notion of government, specifically the nominative and the accusative Cases. The accusative Case is usually given to the complement of a verb whereas the nominative Case is allocated to the specifier. All Noun Phrases are usually taken as Case-inherent or in other words, there should always be a value for Case either nominative or the accusative one by following the traditional name (DeArmond, 2002).

In addition, Chomsky's Case theory observes that an NP must get its specific place in the structure of the sentence, and that specific place is assigned by the case markers. In English language Verbs and Prepositions may Assign Nominative and Accusative case to the NPs, but Nouns and Adjectives have no ability to mark the cases in a sentence. In English language Verbs follow Nominative case, and Accusative Case is followed sometimes by a verb and sometimes by a preposition. But in Urdu language Nominative and Accusative cases come together, following the verb or an indirect object and it has also been observed that how Urdu has got some other cases-ergative, genitive and dative which are not found in English language. Instead English language has only two cases. It is for this purpose that the research has decided to find similarities and differences among the two languages with purpose to highlight important grammatical considerations to develop effective English language techniques for second or foreign language learners.

\section{Data Analysis}

The examples, below in this section, have been taken from New Headway Elementary Workbook by Liz and John Soars (2003):

\subsection{Nominative cases in English and Urdu:}

- I'm from France(New Headway Elementary Workbook, 2003)

- Mai France sa hu.

- You are English

- $\underline{\text { Aap }}$ (tum depending on level of formality) angraiz hain.

- She doesn't live in a city.

$\circ \quad$ Wo shehar me nahi rehti.

- $\quad$ School starts at six o' clock. 
○ School chai bujay shuroo hota ha.

- Sara thinks her house is very small.

- Sara ka kahyal ha k uska ghur buhat chota ha.

- $\quad$ He learned to play the piano.

○ Usna piano bujaana seekha.

- I don't know the answer.

- Mujha jawaab nahi pata.

- We often talked on the telephone.

- Humna akser phone pa baat ki.

- It was my first day at school

$\circ \quad \underline{Y e}$ mera school me pehla din tha.

In the above examples, "I, you, she, school, our, He, It, and we" have shown variations in their nominative properties when got translated into Urdu language. It is obvious that in Urdu there are some other words which add to the nominative case such as "na", and "ka" (ergative and genitive/possessive) but not at all times we need to add them with the noun as we can see that some nominative from examples 1-4 and then in examples 9 remain nominative only and do not take any other case when translated into Urdu. It is also for this reason that Urdu speakers when learn English language then use incorrect pronouns and nouns as nominative as Miriam Butt (1994) stated that nominative case in Urdu is not realized phonologically and taken as null and also there is a different word order in Urdu that leads to difficulties for those who learn English as a second or foreign language.

\subsection{Accusative case and its Relation to Verb in English and Urdu}

- I play tennis.

○ Mei tennis khailti hu.

- I left the party.

- Mena party chorhdi

- She opened her eyes.

○ Usnei apni aankhain kholein.

- She took the frog.

○ Usne maindak pukra.

- He hasn't got any CDs. 
○ Usk paas koi CDs nahi hain.

- Peter didn't pass the exam.

- Peter na exam pass nahi kia.

- She loves them.

○ Wo unsa piar krti ha.

- He doesn't write letters.

○ Wo khat nahi likhta.

- My daughter speakes French and German.

$\circ$ Mere beti Fransisi and German bolti hai.

- I didn't see Sandy.

○ Mena Sandy ko nahi daikha.

It is obvious in all these underlined examples in bold that accusative follows the verb in case of English language but in Urdu verb follows accusative. It is also for this reason that language learners face problems and usually put verb in English at the end as they do in Urdu.

\subsection{Accusative Case and its Relation to Preposition in English and Urdu}

- I don't like going to cinema.

○ Mujhay cinema jaana pasand nahi.

- I arrived at the airport.

- Me airport pohuchi.

- I play tennis with you.

○ Me tumhary saath tennis khailti hu.

- Peter stayed with his grandmother.

- Peter apni grandmother k saath thehra.

- I was at Adam's party on Saturdays.

○ Mei itwar ko Adam ki party pa tha.

- There is a computer next to you.

○ Tumharay saath computer ha.

- I couldn't look at him.

○ Mei uski tarf nahi daikh pai.

- They were not at home.

○ Wo ghur per nahi thay. 
- We girls in the village loved them.

- Hum lurkiyo na gayu me unhain buhat pasand kia.

- I didn't go to school on Monday.

○ Me Monday ko school nahi gai.

The above examples (as underlined) very well present the occurrence of prepositions in English and post positions in Urdu. Accusative follows prepositions in case of English sentences but prepositions come after accusative in Urdu language. It is also the situation that Urdu speakers face great difficulties in understanding prepositional phrases in English and remain confused in their usage in English sentences. Sometimes there are no prepositions when English sentences got translated into Urdu as we can see in examples: 1 and 2 and this is also the reason that Urdu speakers at times do not use prepositions while making English sentences.

\subsection{Accusative case and its relation to Adjective in English and Urdu}

- It's an old house.

○ Ye aik purana(qadeem) ghur ha.

- My aunt lives in an old beautiful house near the sea.

- Mere anti aik pranay(qadeem) or khoobsoorat ghur me rehti hain jo samuhdar k qareeb ha.

- I saw a famous TV star at Peter's party.

- Mena aik mashoor TV star ko Peter ki party pa daikha.

- Sally didn't buy the red shoes.

$\circ$ Sally na surkh jootay nahi khareeday.

- There is a good film on TV tonight.

- Aaj TV pa aik achi film lugay gi.

- She'd like some new clothes for her birthday.

○ Wo apni salgirah pa kuch nava kapray laina chahy gi.

- My car is twenty years old.

○ Mere gardhi bees(20) saal purani ha

In the above mentioned examples, we can see that there are no differences at all in English and Urdu adjectives as in both languages adjectives come before the nouns. However 
this is the situation in case of attributive nature of adjectives (since we know adjective can be attributive and predicative both).Yet we find differences in predicative nature of adjectives when adjectives follows the auxiliary verbs. For instance in the example 7, in case of Urdu language auxiliary "ha" comes at the end of the sentences but in case of English it comes before the adjective.

\section{Conclusion \& Recommendations}

English and Urdu languages possess both similarities and differences in terms of their nominative and accusative properties. In case of nominative, the both languages consider those noun and pronoun as nominative which are responsible for performing any action or involved in any actions but Urdu shows some other cases like dative and ergative which are not found in English language but are marked on the noun in case of Urdu language. Secondly, in both English and Urdu, nominatives have got relation with verbs and according to person, number and gender they are marked.

Moreover, In both languages, Accusative cases show diverse patterns in case of their relations to verbs and prepositions but similar patterns in terms of their relation to adjective except for predicative nature of adjectives. The understanding of these similar and diverse patterns of English and Urdu nominative and accusative properties can develop better understanding of English and Urdu grammar and effective teaching strategies can also be adopted and adapted in order to make students learn English in a better way.

Further research can be conducted on variations of genitive and dative cases on English and Urdu. Some local languages as spoken in Pakistan like Hindko, Pothohari, Balti ,Saraiki, Pushto etc can also be compared in terms of their nominative and accusative properties with English language as English is second language in Pakistan and people face difficulties in learning language but understanding can make the learning process somehow easy for them.

\section{References}

Ali, A., Hussain, S., Malik, K., \& Siddiq, S. Study of Noun Phrase in Urdu.

Asaad, Z. F. (2013, November 18). Case theory. Retrieved from http://www.slideshare.net/zhianasaad/case-theory-28365638

Blake, B. J. (2001). Case. Cambridge University Press.

Butt, M. (n.d.). The Structure of Urdu - Case. Retrieved from http://citeseerx.ist.psu.edu/viewdoc/download?doi=10.1.1.708.2327\&rep=rep1\&type $=\mathrm{pdf}$ 
Pakistan Journal of Humanities and Social Sciences, 7(4), 2019

Butt, M., King, T. H., \& Ramchand, G. (1994). Theoretical perspectives on word order in South Asian languages (No. 50). Center for the Study of Language (CSLI).

Butt, Miriam. "Theories of Case", 2004. Cambridge University Press.

Butt,M. \& King H.T (2001). "Non- Nominative Subjects in Urdu: A Computational Analysis". International Symposium on 'Nonnominative Subjects' organized by ILCAA, Tokyo

Carnie, A. (2001). Syntax. Oxford: Blackwell.

Case Theory. (n.d.). Retrieved from English Language and Linguistics Online: http://www.ello.uos.de/field.php/SyntacticTheory/GBCaseTheory

Chomsky, N. 1981. Lectures on government and binding. Dordrecht: Foris. [7th edition 1993].

DeArmond, D. R. (2002). Case Theory. Retrieved from http://www.sfu.ca/person/dearmond/322/course.outline.322.htm

Downe-Wamboldt, B. (1992). Content analysis: Method, applications, and issues. Health Care for Women International, 13, 313-321.

Durrani, N. (n.d.). System for Grammatical relations in Urdu. Retrieved from http://homepages.inf.ed.ac.uk/dnadir/system_grammatical_relations.pdf

Gimm, S. (2007). Subject Marking in Hindi/Urdu: A Study in Case and Agency. ESSLLI Student Session. Malaga, Spain.

Haspelmath, M. (2006). Terminology of case. Retrieved from http://email.eva.mpg.de/ haspelmt/CaseTerminology.pdf

Hsieh, H. F., \& Shannon, S. E. (2005). Three approaches to qualitative content analysis. Qualitative health research, 15(9), 1277-1288.

Keskin, C. (2009). Subject Agreement-Dependency of Accusative Case in Turkish or Jumpstarting Grammatical Machinery. LOT.

Kondracki, N. L., \& Wellman, N. S. (2002). Content analysis: Review of methods and their applications in nutrition education. Journal of Nutrition Education and Behavior, 34, 224-230.

Krathwohl, D. R. (1998). Methods of educational \& social science research: An integrated International Journal of Education ISSN 1948-5476 2010, Vol. 2, No. 2: E1 14 www.macrothink.org/ije approach (2nd ed.). White Plains, NY: Addison Wesley Longman, Inc.

Liz, \& Soars. (2003). New Headway Elementary Level Workbook. Oxford University Press.

Masica, Colin (1991), The Indo-Aryan Languages, Cambridge: Cambridge University Press, ISBN 978-0-521-29944-2.

Mirza, B. R. (2014, March 23). Retrieved from http://www.slideshare.net/brmirza/casetheory-in-punjabi-language-syntax-presentation

Oxford English Dictionary, Oxford University Press, 2007 http://www.oed.com/

Weber, R. P. (1990). Basic content analysis. Beverly Hills, CA: Sage.

WordNet - Princeton University Cognitive Science Laboratory, 1998 $\mathrm{http}: / /$ wordnet.princeton.edu

Wyse, S. E. (2011, September 16). What is the Difference between Qualitative Research and Quantitative Research? Retrieved from Snap Surveys: http://www.snapsurveys.com/blog/what-is-the-difference-between-qualitativeresearch-and-quantitative-research/ 